JADARA

Volume 6 Number 2

Article 3

November 2019

\title{
Guidelines for Submitting Manuscript
}

None None

None

Follow this and additional works at: https://repository.wcsu.edu/jadara

\section{Recommended Citation}

None, N. (2019). Guidelines for Submitting Manuscript. JADARA, 6(2). Retrieved from

https://repository.wcsu.edu/jadara/vol6/iss2/3 


\section{Guidelines for Submitting Manuscript}

The Journal of Rehabilitation of the Deaf invites manuscripts concerned, primarily, with research, innovations, patterns of service, and other topical areas related to the adult deaf population. The Journal wishes to serve as a vehicle for dissemination of materials of interest to the field and to provide a forum for dialogue between and among people engaged in working with adult deaf people. It is not concerned with simply reporting research studies, but research reports may be considered where implications of importance are made clear.

The following are guidelines authors should follow in submitting manuscripts:

1. Include two clear copies.

2. Leave margin of $1 \frac{1 / 2}{2}$ inches on each side of the paper.

3. Manuscripts should be typed and double spaced.

4. Name, position title, and place of employment of the authors should appear with the title.

5. Footnotes are to be avoided.

6. Format (including references) should follow the prescribed style in the publication manual of the American Psychological Association (available from APA, 1200 Seventeenth Street, N.W., Washington, D.C. 20035).

7. Submit manuscripts to Glenn T. Lloyd, Ed.D., Editor, Journal of Rehabilitation of the Deaf, Deafness Research and Training Center, New York University, 80 Washington Square East, New York, New York, 10003. 